\title{
O Plano Trienal no contexto das relações entre Brasil e Estados Unidos (1962-1963)
}

\author{
FELIPE PEREIRA LOUREIRO*
}

The Three-Year Plan in the context of the US-Brazilian relations (1962-1963). The paper analyses the US-Brazilian relations during the formulation and implementation of the Three-Year Plan by the government of João Goulart. The evidence suggests the limited economic assistance offered by the United States to Brazil, driven by political causes, played a major role in the Three-Year Plan's demise. It is argued that Goulart's links with the radical left, particularly with groups seen as communists by Washington, was the main reason behind US decision of blocking resources. The conclusions are relevant because scholars have emphasized domestic reasons only to explain the failure of the Three-Year Plan.

Keywords: economic policy; Three-Year Plan; João Goulart; US-Brazilian relations.

JEL Classification: N16; N46; F59.

No início da década de 1960, a economia brasileira vivia um período de dificuldade. Após anos de forte crescimento, os efeitos da política expansionista da administração Kubitschek (1956-1961) faziam-se sentir, particularmente a elevação da inflação e o desequilíbrio no balanço de pagamentos. ${ }^{1}$ Inúmeras foram as tentativas executadas pelos governos Jânio Quadros e João Goulart (1961-1964) para superar esses problemas. A mais importante foi o Plano Trienal de Desenvolvimento Econômico e Social. Elaborado no final de 1962 por Celso Furtado, então Ministro Extraordinário do Planejamento de Goulart, o Plano visava manter o crescimento econômico por meio de uma abordagem gradualista de combate à inflação,

\footnotetext{
* Doutorando em Histórica Econômica da Faculdade de Filosofia, Letras e Ciências Humanas da Universidade de São Paulo e Bolsista do CNPq. E-mail: fpeloureiro@gmail.com. Submetido: 5/ agosto/2011; Aprovado: 9/janeiro/2013.

${ }^{1}$ Para um balanço da economia brasileira no período, ver Baer (1979, pp. 181-220).
} 
buscando baixar o aumento no nível geral de preços de $50 \%$ para $10 \%$ ao ano até 1965. O Plano Trienal, porém, teria vida curta. Em seis meses ele seria abandonado. ${ }^{2}$

Há consenso entre estudiosos sobre a importância de um eventual sucesso do Plano Trienal para a consolidação do governo Goulart. A falência do programa econômico de Furtado certamente contribuiu para a instabilidade que levaria ao golpe militar de 1964. Muitos autores debruçaram-se sobre as razões pelas quais o Plano teria fracassado. ${ }^{3}$ Apesar de essa pergunta ter recebido as mais diferentes respostas, todas se focaram em fatores de ordem doméstica, tais como pressões das classes sociais pelo relaxamento da política de estabilização, conflitos entre os poderes Executivo e Legislativo, uma suposta falta de interesse do presidente Goulart em apoiar o Plano por razões eleitorais, e até a inexistência de um adequado instrumental de política econômica. Ressalta-se a ausência de estudos detalhados sobre as relações financeiras entre os governos brasileiro e norte-americano no período. Essa lacuna é significativa na medida em que os próprios membros da administração Goulart reconheciam a importância do aporte de recursos estrangeiros, em especial dos Estados Unidos, para o sucesso do Plano. Os compromissos externos do país para o triênio 1963-1965 eram consideráveis. Apenas em 1963 o passivo potencial era de quase US\$ 900 milhões, o que representava mais da metade do valor das exportações brasileiras em $1962 .{ }^{4}$ Sem uma substancial ajuda externa, seria impossível conciliar contenção inflacionária e crescimento econômico.

$\mathrm{O}$ artigo analisa as relações Brasil-Estados Unidos no contexto do Plano Trienal, focando-se nas negociações de auxílio financeiro. Foram utilizadas basicamente fontes oficiais dos governos brasileiro e norte-americano, em especial a comunicação entre a embaixada dos Estados Unidos no Rio de Janeiro e órgãos governamentais em Washington. Argumenta-se que a falta de ajuda externa dos Estados Unidos ao Brasil foi um dos fatores fundamentais para a falência do Plano Trienal, juntamente com os aspectos de ordem doméstica tradicionalmente destacados pela literatura, sobretudo a intensificação do conflito distributivo entre capital e trabalho, bem como as pressões de entidades empresariais e de trabalhadores em prol da flexibilização das metas de estabilização. Assinala-se que o governo brasileiro teria tido poucas condições de atender a essas pressões domésticas exatamente por causa da inflexibilidade de Washington, que condicionou a liberação de recursos à implementação de um rígido programa de estabilização. O mais interessante, porém, é que a análise da documentação sugere que cálculos econômicos

\footnotetext{
${ }^{2}$ Para o Plano Trienal, ver Abreu (1990, pp. 206-9); Bandeira (1983, pp. 89-99); Brasil (1962); Daland (1967, pp. 143-71); Macedo (1987, pp. 52-67); Mesquita (1992, pp. 165-236); Monteiro (1999, pp. 87-98); Silva (1992, pp. 147-94); Sochaczewsky (1991, pp. 210-7); e Wells (1977, pp. 221-8).

${ }^{3}$ Ver Araújo et al. (2006); Ferreira (2011, pp. 327-32); Figueiredo (1993, pp. 92-112); Fonseca (2004); Leff (1977, pp. 102-3); Loureiro (2010); Macedo (1987, pp. 64-5); Monteiro (1999, pp. 135-38); Silva (1992); Sochaczewsky (1991, pp. 210-7); e Sola (1998, pp. 350-99).

${ }^{4}$ CIA Memorandum, 3936/62, John F. Kennedy Library, Boston (a seguir JFKL), National Security Files (a seguir NSF), Papers of Ralph Dungan (a seguir PRD), Box 390, Folder Brazil general (a seguir BG) 11/62-12/62 (a seguir suprimem-se as designações box e folder), p. 1.
} 
estiveram longe de ser predominantes na determinação do posicionamento norte-americano. Mais importantes foram as questões de natureza política, particularmente a relação do presidente Goulart com grupos considerados comunistas por Washington. $\mathrm{Na}$ visão do governo dos Estados Unidos, o comprometimento de Goulart com a implementação de um rígido programa de estabilização seria sobretudo um meio para influenciar a orientação política do presidente brasileiro.

Para além desta introdução, divide-se o artigo em quatro seções. Na primeira seção faz-se uma revisão da literatura sobre o Plano Trienal. Nas segunda e terceira partes examinam-se as relações entre os governos Goulart e Kennedy durante o processo de formulação e de execução do programa, respectivamente. $\mathrm{Na}$ quarta seção apresentam-se as conclusões.

\section{O PLANO TRIENAL E A LITERATURA}

As explicações para o fracasso do Plano Trienal podem ser divididas em três grupos. Um aspecto comum entre eles é a ênfase em fatores de ordem doméstica. O primeiro grupo é composto de estudiosos que identificam no presidente Goulart o principal responsável pela falência do programa. Werner Baer, por exemplo, argumenta que Goulart não teria tido nem "meios" nem "vontade" para implementar as medidas de estabilização; já Nathaniel Leff, Paulo Castro e Márcio Ronci dão ênfase à "inabilidade" e à falta de competência do presidente no comando da política econômica. ${ }^{5}$

Um segundo grupo de autores ressalta as incongruências internas do Plano Trienal e/ou os erros das autoridades da área de política econômica. Roberto Macedo aponta para um diagnóstico "simplificado" do programa sobre inflação, bem como para uma suposta negligência do Plano Trienal na delimitação de uma política salarial para o setor privado. ${ }^{6}$ Antônio Sochaczewsky argumenta que teria sido "surpreendente" o fato de as autoridades monetárias não terem aplicado medidas para restringir as operações dos bancos comerciais em 1963, o que, segundo o autor, teria sido determinante para o descumprimento das metas de inflação. ${ }^{7}$ Mário Mesquita, por sua vez, ressalta que técnicos do governo teriam subestimado os impactos das medidas de "inflação corretiva" sobre o nível de preços no início de 1963, criando um efeito dominó sobre as demais metas da política econômica. ${ }^{8}$

A terceira e última abordagem identifica na exacerbação dos conflitos e pressões

\footnotetext{
${ }^{5}$ Baer (1979, p. 191); Castro e Ronci (1992, p. 187); Leff (1977, p. 152).

${ }^{6}$ Macedo (1987, p. 63).

${ }^{7}$ Sochaczewsky (1991, pp. 221-2).

${ }^{8}$ Convencionou-se chamar de "inflação corretiva" o aumento do nível geral de preços decorrente de medidas que visassem reduzir gastos do governo, evitando a emissão de papel-moeda para cobrir déficits do Tesouro. Exemplo nesse sentido foi o reajuste das tarifas de serviços públicos, implementada pelo governo Goulart no início de 1963. Ver Mesquita (1992 p. 187-9).
} 
sociais uma variável-chave para o fracasso do Plano Trienal. Para Sérgio Monteiro e Pedro Dutra Fonseca, o Plano Trienal teria sido formulado com o intuito de garantir "legitimidade" ao governo brasileiro junto a credores internacionais. A partir do momento, porém, em que as condições domésticas teriam se tornado desfavoráveis, sobretudo no que se refere às pressões de trabalhadores e empresários, o governo Goulart, como todo governo "populista", teria deixado de "parecer forte", abandonando o programa de estabilização e voltando a privilegiar políticas expansionistas em prol do crescimento econômico. ${ }^{9}$ Argelina Figueiredo também argumenta que reações de empresários e trabalhadores teriam tido papel central no fracasso do Plano Trienal, destacando a ausência de mecanismos institucionais capazes de garantir o cumprimento das metas de política econômica pelos grupos sociais, em especial no que se refere ao controle de preços. ${ }^{10}$ Lourdes Sola, por sua vez, apesar de ter ressaltado o "processo de exacerbação das tensões internas ao pacto social", elenca ainda vários outros fatores para explicar a falência do programa, entre os quais conflitos entre os poderes Executivo e Legislativo, erros técnicos e ausência de instrumentos adequados de política econômica, tais como um típico Banco Central. ${ }^{11}$

Após décadas de debate, a terceira perspectiva vem se consolidando como a mais sólida das três abordagens, apesar de ainda não existir um consenso sobre o tema na literatura. Pesquisas recentes apresentaram evidências que reforçaram a ideia da centralidade do conflito distributivo entre empresários e trabalhadores para o fracasso do Plano Trienal, enfatizando a importância tanto do período de formulação quanto do de implementação do programa para a compreensão das razões de seu insucesso. ${ }^{12}$ Essa ênfase em fatores domésticos, porém, apesar de importante, é insuficiente para explicar o malogro do Plano Trienal. A fim de compreender o porquê de a administração Goulart não ter tido condições de flexibilizar suas metas de política econômica, acomodando-as às pressões sociais internas, é fundamental analisar o quadro de restrição internacional enfrentado por Jango, sobretudo o posicionamento do governo norte-americano na liberação de recursos financeiros. Dada a amplitude das obrigações internacionais do Brasil no triênio 1963-1965, que estavam muito acima da capacidade de pagamento nacional, a ajuda norte-americana era fundamental para evitar a declaração de uma moratória pelo Brasil - atitude que traria sérias consequências para a manutenção do nível das atividades domésticas, sobretudo devido aos efeitos sobre o fluxo de importações. ${ }^{13} \mathrm{~A}$ análise dos fundamentos da posição do governo Kennedy na questão da

\footnotetext{
${ }^{9}$ Fonseca (2004, p. 620); Monteiro (1999, pp. 137-8).

${ }^{10}$ Figueiredo (1994, pp. 109-13).

${ }^{11}$ Sola (1998, pp. 349-51, p. 368, pp. 386-91, pp. 397-9).

12 Ver, principalmente, Loureiro (2010 e 2012, cap. 7).

${ }^{13}$ Para maiores informações sobre a frágil situação financeira do Brasil no período, ver Embassy Report A-474, "Brazilian Financial Crisis", 26.10.1962; e Telegram of the US Embassy in Brazil to the Departament of State (a seguir Embtel), 1436, 29.11.1963, National Archives and Records Administration (a seguir NARA), Record Group (a seguir RG) 84, 136, 501.
} 
ajuda financeira ao Brasil contribuirá, portanto, para preencher uma importante lacuna sobre as razões do fracasso do Plano Trienal. Esse tema é tratado nas próximas seções do artigo.

\section{O CONTEXTO DE FORMULAÇÃO DO PLANO TRIENAL E O GOVERNO KENNEDY}

Em outubro de 1962, uma equipe norte-americana liderada pelo general William Drapper foi enviada ao Brasil para analisar a situação financeira do país. Após se encontrar com empresários e autoridades, o grupo produziu um relatório controverso sobre a administração Goulart. "O Brasil está na iminência de uma catástrofe financeira”, assinalou Drapper. Propôs-se a intensificação de uma política de "linha dura" na concessão de recursos. Os Estados Unidos deveriam manter somente "ajuda limitada" até que Goulart fosse retirado do poder. Supunha-se que, sem apoio financeiro, os problemas socioeconômicos se intensificariam de tal modo que os militares dariam um golpe para restabelecer a ordem. No caso de Washington preferir manter uma "assistência econômica de curto prazo", recomendou-se o condicionamento desse auxílio a um programa de estabilização de "resultados imediatos”. No entanto, a formulação do Plano Trienal — ou seja, uma via gradualista de combate à inflação - dificultava as coisas. É nesse sentido, concluiu Drapper, que não seria recomendável aos Estados Unidos "adiarem uma crise" por meio da concessão de mais recursos ao Brasil. ${ }^{14}$

As conclusões do relatório Drapper não foram aceitas unanimemente no governo Kennedy. Lincoln Gordon, embaixador norte-americano no Brasil, discordou da previsão de que Goulart seria retirado do poder uma vez que os Estados Unidos decidissem impor uma política de "linha dura". Isso só seria bem-sucedido, afirmou Gordon, se Goulart desrespeitasse a Constituição ou apoiasse uma tentativa de golpe comunista - situações vistas como improváveis naquele contexto. Considerou-se ainda "politicamente inviável" que Washington pressionasse o governo brasileiro a solucionar o problema da inflação em apenas um ano. Um programa de estabilização "gradual” seria mais apropriado diante das "limitações atuais" do país. ${ }^{15}$

Outros membros do governo Kennedy, no entanto, mostraram-se favoráveis à abordagem de Drapper. Frank Sloan, Secretário Assistente para Assuntos Americanos, afirmou que "a manutenção de Goulart no poder é prejudicial aos interesses dos Estados Unidos". Sloan recomendou que Washington desenvolvesse um "programa passo a passo" a fim de não dar escolha ao presidente brasileiro: ou

\footnotetext{
${ }^{14}$ Report to the President by the Interdepartmental Survey Group on Brazil, 03.11.1962, JFKL, NSF, 13, BG 11/1/62-11/15/62.

${ }^{15}$ Telegram of the U.S. Embassy in Brazil to the Departament of State (a seguir Embtel), 924, Section I, 02.11.1962, JFKL, President Office's Files (a seguir POF), 112, 16, pp. 2-3.
} 
Goulart aceitava esse programa, separando-se "de uma vez por todas" dos comunistas, ou, em caso contrário, haveria seu envolvimento "inequívoco" com a esquerda radical, dando aos militares "tanto o pretexto quanto o apoio público para removê-lo". A aplicação de um rígido plano de estabilização faria parte de tal "programa passo a passo", para além de demandas em áreas como movimento sindical e política externa. ${ }^{16}$

Apesar de o Departamento de Estado ter acatado parte das críticas ao relatório Drapper, a ideia de um "programa passo a passo" para comprometer ou separar Goulart dos comunistas também ganhou apoio em Washington. Em resposta aos comentários de Lincoln Gordon, o Secretário de Estado Dean Rusk afirmou que "nós reconhecemos que não é razoável esperar êxito completo de [um plano de] estabilização em menos de um ano ou dois”. Por outro lado, os Estados Unidos estariam propensos a ajudar financeiramente o governo Goulart somente junto com outros credores e baseados em um conjunto de condições, tais como a implementação de um "fundamentado programa de estabilização", a resolução dos casos de expropriação de subsidiárias norte-americanas, ${ }^{17} \mathrm{o}$ abandono da Política Externa Independente (PEI), e o fim dos vínculos de Goulart com "comunistas". ${ }^{18}$

Para piorar a situação, em novembro de 1962, Goulart ameaçou Lincoln Gordon com a possibilidade de o Brasil aceitar "ajuda econômica soviética” se o governo Kennedy não fornecesse recursos para o Plano Trienal. Sabia-se que um rompimento com os Estados Unidos traria enormes dificuldades para o Brasil, entre as quais racionamento de energia e escassez de importações. Se o rompimento ocorresse, disse Goulart, ele próprio "denunciaria os Estados Unidos por depreciarem os termos de troca latino-americanos", a fim de "preparar a população para enfrentar os sacrifícios necessários”. Goulart afirmou ainda que acreditava "que a maior parte da América Latina se juntaria ao Brasil na oposição contra os Estados Unidos”. Segundo Gordon, a posição do presidente refletia a influência de Celso Furtado, para quem a economia brasileira seria "viável sem o auxílio norte-americano". ${ }^{19}$

As ameaças de Goulart acarretaram sérias consequências. O Departamento de Estado ordenou estudos sobre a possibilidade de assistência soviética ao Brasil e as alternativas apresentadas à economia brasileira em caso de rompimento com os

\footnotetext{
${ }^{16}$ Memo, Frank K. Sloan to Edwin Martin, 14.11.1962, NARA, RG 59, 3, Mis 5d, pp. 2-6.

17 O governador do Rio Grande do Sul, Leonel Brizola (PTB), expropriou subsidiárias locais da American Foreign and Power (AMFORP) e da International Telephone and Telegraph (ITT) em $1959 \mathrm{e}$ 1962, respectivamente, depositando quantias simbólicas como indenização. De acordo com a Constituição de 1946, o caso deveria ser resolvido pela justiça estadual. Ver Bandeira (1983, pp. 49-52), Dulles (1970, pp. 170-1) e Leacock (1990, pp. 85-8).

${ }^{18}$ Telegram of the Department of State to US Embassy in Brazil (a seguir Deptel), 1147, 15.11.1962, JFKL, POF, 112, 16, pp. 1-3. A PEI possuía três linhas básicas de ação: estreitamento do vínculo do Brasil com o Terceiro Mundo; restabelecimento de relações diplomáticas com países do bloco socialista; e defesa do princípio de autodeterminação dos povos. Ver Storrs (1973).

${ }^{19}$ Embtel 1001, Section II, 23.11.1962, JFKL, POF, 112, 16, pp. 2-3.
} 
Estados Unidos..$^{20}$ Os resultados foram animadores para Washington. Estimou-se que o Brasil enfrentaria déficit de US\$ 1,35 bilhão no balanço de pagamentos. Para tentar fechar esse déficit, o país poderia cortar remessas de capital ao exterior e ampliar relações comerciais com países socialistas. Ainda assim restariam US\$ 600 milhões em aberto. A única forma de cobrir esse valor seria via corte de importações essenciais. Isso, porém, acarretaria "forte impacto negativo na economia". ${ }^{21}$ Por isso, "nós achamos que qualquer brasileiro razoável, por mais esquerdista que seja, hesitaria em procurar [...] rompimento com os Estados Unidos nesse estágio". ${ }^{22}$

Sabendo de sua posição de superioridade, Washington passou a discutir o que deveria fazer após as ameaças de Goulart. Muitos argumentaram a favor do condicionamento da ajuda financeira à mudança de orientação política do governo brasileiro. Ressaltou-se que medidas favoráveis na área econômica não seriam suficientes se o regime continuasse a manter "sindicalistas" e "criptocomunistas" em posições governamentais. ${ }^{23}$ Segundo Lincoln Gordon, seria preciso "fazer de demandas políticas o preço do nosso apoio econômico". Se isso falhar, afirmou, "nós precisamos considerar todos os meios possíveis para promover [a] mudança do regime". ${ }^{24}$

Em 11 de dezembro de 1962, o Comitê Executivo do Conselho de Segurança Nacional norte-americano discutiu possíveis cursos de ação sobre o Brasil: (a) "observar e esperar" a evolução dos acontecimentos; (b) colaborar para a queda de Goulart; e (c) "buscar mudança na orientação política e econômica" do regime. Votou-se pela terceira alternativa, porém com duas ressalvas. Esse esforço de modificação do governo brasileiro deveria acontecer por meio de uma "grande confrontação com Goulart”, a ser aplicada por um "emissário especial”. O escolhido foi o próprio irmão do presidente, Robert Kennedy, então Procurador-Geral de Justiça. Além disso, estabeleceu-se que "os requisitos e as possibilidades de mudança para a alternativa B deve[ria]m ser mantidos sob ativa e contínua consideração". ${ }^{25}$

No encontro entre Goulart e Bob Kennedy, ocorrido uma semana depois, o emissário norte-americano foi direto ao ponto: o presidente Kennedy estaria "preocupado" com alguns aspectos da "conjuntura brasileira", entre os quais os "muitos sinais de infiltração comunista ou de nacionalistas de extremaesquerda" no governo, nas Forças Armadas e na "liderança dos sindicatos de trabalhadores", bem como a "deterioração da situação econômica do Brasil". Bob Kennedy também fez menção à importância de as atividades empresariais serem tratadas "com justiça",

\footnotetext{
${ }^{20}$ Deptel 1188, 27.11.1962, JFKL, POF, 112, 16.

${ }^{21}$ Embtel 1072, 03.12.1962, Section I, Idem.

${ }^{22}$ Idem, Section II.

${ }^{23}$ Ibidem, Section III.

${ }^{24}$ Embtel 977, 19.11.1962, Section I, JFKL, POF. 112, 16, pp. 1-2.

${ }^{25}$ O Estado de São Paulo (a seguir OESP), 19.12.1962, p.2 .
} 
em particular o pagamento de "indenização adequada" às empresas expropriadas pelo Estado. Ressaltou-se que os Estados Unidos queriam “cooperar com o Brasil”, mas que antes o presidente deveria "pôr a casa em ordem". ${ }^{26}$ Em sua resposta, Goulart argumentou que ele teria sido obrigado "a organizar as forças populares" para ficar no poder, pois as "elites" lhe teriam "virado as costas"; e que os problemas econômicos brasileiros deviam-se à deterioração dos termos de troca, e não à irresponsabilidade governamental. Segundo Goulart, "a população brasileira escuta da imprensa" notícias sobre as dificuldades econômicas com os Estados Unidos, enquanto países socialistas oferecem empréstimos de longo prazo ao Brasil. Isso geraria uma "pressão" que não se poderia ignorar, apesar de ele, Goulart, não ser comunista e ter lutado contra os comunistas desde o início de sua carreira. ${ }^{27}$

Insatisfeito com a resposta, Bob Kennedy insistiu que Goulart não havia compreendido a preocupação do presidente norte-americano, particularmente sobre a presença de membros do governo brasileiro contrários aos Estados Unidos. Irritado, Goulart demandou "de modo ríspido" a Bob Kennedy que nomeasse essas pessoas. O Procurador-Geral disse que "não queria entrar em nomes específicos" e mandou Lincoln Gordon "comentar". O embaixador afirmou que havia alguns órgãos do governo em que tal "problema [era] agudo", tais como Petrobras, Ministério de Minas e Energia, Superintendência do Desenvolvimento do Nordeste (SUDENE), e Banco Nacional de Desenvolvimento Econômico (BNDE). O presidente respondeu que existiam certos membros "que professavam posições antiamericanas" no "baixo escalão" desses órgãos, mas que eles não teriam poder para influenciar as políticas do governo. Goulart reiterou que os Estados Unidos poderiam ter "confiança" de que ele não "cairia no jogo dos comunistas". ${ }^{28}$

A visita de Bob Kennedy representou um ultimato do governo norte-americano a João Goulart: ou mudava-se a orientação política do regime, ou não haveria apoio financeiro ao Plano Trienal. Questões de natureza econômica, como a implementação de um eficiente programa de estabilização, e a resolução dos litígios envolvendo subsidiárias de empresas norte-americanas, apesar de importantes, não eram tão essenciais para Washington quanto a "aliança" de Goulart com os "comunistas". Questões de ordem econômica também entrariam, porém, como condições de auxílio ao Brasil. Isso se justifica porque elas constituíam uma agenda inaceitável para a esquerda radical, além de representarem interesses de grupos empresariais nos Estados Unidos. A pressão feita pela administração Kennedy para que o governo brasileiro aplicasse um rígido programa de estabilização representava um meio para atingir um objetivo maior (a ruptura da aliança de Goulart com os comunistas), mas também um fim em si mesmo.

Vale lembrar que, desde sua atuação como Ministro do Trabalho de Getulio Vargas em 1953, Goulart manteve contatos com comunistas no meio sindical. As

\footnotetext{
${ }^{26}$ Embtel A-710, 19.12.1962, JFKL, NSF, 13A, BG, 12/16/62 - 12/31/62, p. 2.

${ }^{27}$ Idem, pp. 5-10.

${ }^{28}$ Ibidem, pp. 12-5.
} 
restrições dos norte-americanos a Jango, portanto, vinham de longe. Goulart sabia que comunistas e outros grupos de esquerda tinham suporte popular, principalmente entre os trabalhadores urbanos. Os comunistas, por exemplo, possuíam forte presença em sindicatos de setores-chave da economia, como marítimos, ferroviários e portuários. Para um presidente como Jango, que quase havia sido deposto pelos militares em agosto de 1961, quando do episódio da renúncia de Quadros, manter esse apoio era fundamental. No entanto, isso significaria manter contatos com grupos indesejados por Washington, como Bob Kennedy havia deixado claro. ${ }^{29}$ Diante do impasse, resta saber até onde Goulart estaria disposto a trilhar em troca dos recursos financeiros norte-americanos.

\section{O CONTEXTO DE IMPLEMENTAÇÃO DO PLANO TRIENAL E O GOVERNO KENNEDY}

O governo Kennedy foi o primeiro a ter acesso ao Plano Trienal. Dias antes de o programa ter sido apresentado ao Conselho de Ministros, em 18 de dezembro de 1962, Goulart organizou um encontro entre Celso Furtado, Lincoln Gordon e Ralph Korp (adido financeiro norte-americano). Queria-se que Washington recebesse uma "descrição preliminar dos trabalhos", podendo "fazer comentários em uma fase inicial". Segundo Gordon, não houve condições ali de concluir sobre a "viabilidade" do programa, pois Furtado teria feito apenas uma apresentação "genérica". Mesmo assim, Korp insistiu sobre a importância de o Brasil reatar contatos com o FMI, além de tomar providências para manter o fluxo de capitais externos. Sem isso, argumentou, o Plano Trienal não seria bem-sucedido. ${ }^{30}$

A frágil situação financeira do Brasil demandava ajuda externa imediata. Março de 1963 seria o "mês decisivo", segundo palavras de Gordon. Sem novos recursos, dificilmente o país escaparia da "inadimplência". ${ }^{31}$ Goulart teria alguns meses para mostrar que cumpriria o "conjunto de condições" apresentadas por Bob Kennedy. No geral, o presidente deu sinais de que estava disposto a ceder. Em janeiro de 1963, o governo brasileiro concluiu acordo com a International Telephone and Telegraph (ITT), pagando compensação pela expropriação da subsidiária da empresa no Rio Grande do Sul. ${ }^{32}$ Além disso, Goulart seguiu recomendações quanto à consulta ao FMI. Ainda em janeiro, o governo brasileiro convidou uma missão do Fundo para visitar o país. Sob ordens do Itamaraty, o embaixador do Brasil nos Estados Unidos, Roberto Campos, pediu para que a visita fosse mantida sob sigilo.

\footnotetext{
${ }^{29}$ Embtel A-710, JFKL, NSF, 13A, BG 12/16/62-12/31/62, pp. 5-6, 14. Para a influência dos comunistas nos sindicatos, ver Harding (1973: cap. 10). Para a relação de Goulart com o movimento sindical, ver Gomes \& Ferreira (2007, pp. 81-110).

${ }^{30}$ Embtel 1154, 17.12.1962, JFKL, NSF, 13A, BG, 12/16/62-12/31/62.

${ }^{31}$ Embtel 1436, 29.01.1963.

${ }^{32}$ Embassy Report (a seguir Emprep A-941, 18.02.1963, Idem, 2/63).
} 
A demanda foi parcialmente acatada pelo governo Kennedy. Acordou-se que não seriam feitos esforços nem para mantê-la em segredo nem para publicizá-la. ${ }^{33}$

Dias depois, porém, a United Press International (UPI) misteriosamente divulgaria a notícia sobre a missão do FMI. Visando minimizar o impacto das acusações de que o governo seria "entreguista", as autoridades brasileiras apressaram-se em desmentir o convite, alegando que os técnicos do Fundo teriam vindo apenas para uma "visita de rotina", e não para analisar o Plano Trienal. ${ }^{34}$ A embaixada britânica no Rio insinuou que o vazamento teria sido feito pelo Departamento de Estado. ${ }^{35}$ Caso isso tenha ocorrido, a atitude norte-americana só poderia visar à intensificação das críticas da esquerda radical ao governo Goulart.

Apesar do vazamento da informação, o governo brasileiro não dificultou os trabalhos da missão do FMI. Isso foi considerado pela embaixada norte-americana como mais um sinal de que Goulart estava disposto a ceder. Os técnicos do Fundo chegaram ao Brasil no final de janeiro de 1963, reuniram-se com diversas autoridades, retornando a Washington em uma semana. O grupo informou a Lincoln Gordon que teria ficado "impressionado" com o esforço do Ministro da Fazenda San Tiago Dantas. No entanto, salientou-se que o governo não reunira "evidências suficientes" para provar que seria capaz de implementar um "verdadeiro programa de estabilização”. Exemplo disso estaria no déficit público, cujas estimativas oficiais para 1963 (Cr\$ 300 bilhões) estariam muito abaixo da avaliação feita pelo grupo (Cr\$ 450 bilhões). ${ }^{36} \mathrm{O}$ chefe da missão, Jorge del Canto, reconheceu ainda que o FMI teria "algumas dificuldades conceituais" com a abordagem gradualista do Plano Trienal. ${ }^{37}$

Um dia após a partida da missão do FMI, o governo Kennedy enviou ao Brasil um grupo para discutir o Plano Trienal. Chefiados pelo Subsecretário de Assuntos Americanos Herbert May, a missão travou reuniões com San Tiago Dantas e discutiu vários aspectos da política econômica. No primeiro encontro, May pressionou o Ministro da Fazenda para que controles cambiais fossem extintos. O Subsecretário salientou que essa medida estimularia as exportações brasileiras. May também apresentou preocupações sobre os efeitos de excessivos aumentos salariais para o cumprimento das metas do Plano Trienal. Em resposta, Dantas disse que não poderia assumir compromissos sobre o câmbio naquele momento, mas assegurou que o governo tomaria providências para evitar reajustes salariais acima do nível da inflação. ${ }^{38}$ Nas reuniões subsequentes, discutiram-se os motivos que teriam

\footnotetext{
${ }^{33}$ Embtel 1305, 11.01.1963, NARA, RG 84, 136, 501.

${ }^{34}$ UK Embassy Report to J. Anson, 08.01.1963, The National Archives, Londres (a seguir TNA), Foreign Office's Papers (a seguir FO), 371/172354, p. 2.

${ }^{35}$ Idem, p. 3. Última Hora (a seguir UH), 23.01.1963, p. 4.

${ }^{36}$ Embtel 1463, 04.02.1963, NARA, RG 84, 136, 501.

${ }^{37}$ Embrep A-778, 07.01.1963, NARA, RG 84, 136, 501 p. 1.

${ }^{38}$ Memorandum of Conversation (a seguir MemCon), Dantas, May, 04.02.1963, JFKL, NSF, 13A, BG, 2/63.
} 
levado a administração Goulart a adotar uma abordagem gradualista contra a inflação. Dessas discussões, destaca-se o compromisso assumido pelo Ministro da Fazenda de executar o programa de estabilização em um período inferior a três anos, caso recebesse "mais auxílio internacional que o esperado". ${ }^{39}$

O desempenho do Plano Trienal nos primeiros meses de 1963 também foi elogiado por membros do governo norte-americano. Em relatório enviado ao Departamento de Estado em fevereiro, por exemplo, a embaixada afirmou que seria "justo admitir" que até aquele momento o plano estaria demonstrando "vigor e consistência", tendo avançado "etapas substanciais". ${ }^{40}$ No mês seguinte, em memorando ao presidente Kennedy, Lincoln Gordon assinalou que "o programa vem sendo implementado com uma firmeza de propósitos incomparável no Brasil nos anos recentes". ${ }^{41}$ Em outro documento dirigido a Kennedy, desta vez pelo Departamento de Estado, reconheceu-se que "o Plano contém ingredientes essenciais para um efetivo programa [de estabilização]". ${ }^{42}$

Apesar de todas essas concessões, persistiam as ressalvas de Washington ao presidente brasileiro. O principal motivo era a permanência de figuras "contrárias aos Estados Unidos" dentro do governo, em especial o "criptocomunista” Almino Afonso (Ministro do Trabalho), o "provável comunista" Evandro Lins e Silva (chefe do Gabinete Civil), o "comunista” Raul Ryff (assessor de imprensa da Presidência), o "protegido de Brizola" João Caruso (diretor da Superintendência de Política Agrária, SUPRA), e o "economista de extrema esquerda" Cíbilis Viana (assessor econômico da Presidência). ${ }^{43}$ Por mais que Goulart tivesse avançado em vários aspectos, o presidente continuava a ignorar a principal reclamação dos Estados Unidos: a "infiltração comunista" no governo e nos sindicatos.

Os membros do governo Kennedy lembraram inúmeras vezes seus colegas brasileiros haver esse problema. Em dezembro de 1962, uma semana após o ultimato apresentado por Bob Kennedy, Roberto Campos escutou de um alto funcionário norte-americano que as dificuldades encontradas pelo Brasil na liberação de verbas em Washington não estariam relacionadas a "questões econômicas ou financeiras, mas políticas". ${ }^{44}$ Da mesma maneira, em fevereiro de 1963, na primeira das três reuniões realizadas entre May e Dantas para supostamente discutir o Plano Trienal, o subsecretário norte-americano assinalou que os Estados Unidos não estariam preocupados "apenas com política econômica", mas também com "a orientação política e a infiltração comunista no governo". May assinalou que Washing-

\footnotetext{
${ }^{39}$ Embtel 1514, 11.02.1963, JFKL, NSF, 13A, BG, 2/63.

${ }^{40}$ Embrep A-941, 18.02.1963, p. 7.

${ }^{41}$ MemPres, 07.03.1963, JFKL, NSF, 13A, BG, 3/1/63-3/11/63.

${ }^{42}$ MemPres, 04.03.1963, JFKL, NSF, PRD, 390A, Brazil, 1/63-6/63.

${ }^{43}$ Idem, p. 4; Department of State's Report (a seguir Deprep), 25.01.1963, JFKL, NSF, 13A, BG, 1/63;

"Unfulfilled Commitments of President Goulart", 03.1963, Idem, p. 2.

${ }^{44}$ Deptel 1332, 29.12.1962, JFKL, NSF, 13A, BG, 12/16/62-12/31/62, p. 3.
} 
ton "não teria predileção em financiar uma mudança brasileira para o campo inimigo". 45

As autoridades brasileiras, por sua vez, argumentaram que temores sobre participação comunista no governo eram infundados. O embaixador Roberto Campos, em reunião com Gordon, disse que Almino Afonso teria sido escolhido porque Goulart achava importante ter um Ministro do Trabalho capaz "de extrair dos trabalhadores brasileiros os sacrifícios necessários pelo esforço de estabilização". De forma semelhante, quando confrontado por Herbert May sobre a suposta "infiltração comunista", San Tiago Dantas afirmou que muitos funcionários interpretados como "comunistas" pelo governo Kennedy seriam, na realidade, apenas "nacionalistas". O Ministro da Fazenda também salientou que os "esquerdistas" com cargos políticos constituiriam apenas reflexo do equilíbrio de poder na sociedade. Dantas creditava ao "subdesenvolvimento" essa parcela de apoio social usufruída pela esquerda no Brasil. ${ }^{46}$ Argumentos semelhantes foram empregados por Goulart com Lincoln Gordon. ${ }^{47}$

Seria em contexto de incerteza, portanto, marcado pelas conhecidas reservas do governo Kennedy, que San Tiago Dantas partiria para Washington em março de 1963 para negociar recursos ao Brasil. O Ministro da Fazenda sabia que o êxito de seu programa econômico dependia da ajuda dos Estados Unidos. A frágil posição política do governo, acusado de "entreguista" pela esquerda, criava constrangimentos ao ministro. Um mês antes da viagem, Dantas alertou Herbert May que sua missão em Washington só poderia acontecer "se houvesse chances reais de sucesso", caso contrário ele seria obrigado a renunciar. ${ }^{48}$ Goulart descreveu a situação em termos ainda mais extremos. Em carta a Kennedy, o presidente brasileiro disse que o Plano Trienal seria "o único meio capaz de harmonizar estabilidade econômica, a preservação da paz social e a continuidade democrática" ${ }^{49}$ Outros atores políticos também enxergavam no programa de Dantas "a última chance da democracia no Brasil". ${ }^{50}$ Exageros à parte, tendo em vista o montante de compromissos externos, era evidente que o futuro do Plano Trienal muito dependia do desfecho das negociações em Washington.

A proposta de assistência econômica apresentada por San Tiago Dantas ao governo Kennedy foi audaciosa. Entre refinanciamentos e empréstimos, o Brasil solicitou US\$ 839,7 milhões. Esses recursos seriam distribuídos ao longo de três anos, sendo quase metade com liberação prevista para 1963. Deu-se preferência às instituições que ofereciam condições subsidiadas de empréstimos, ou seja, a Agên-

\footnotetext{
${ }^{45}$ Embtel 1488, 06.02.1963, Idem, BG, 2/63, pp. 1-2.

${ }^{46}$ Embtel 1488, 06.02.1963, pp. 2-3.

${ }^{47}$ Embtel 1602, 23.02.1963, pp. 1-2.

${ }^{48}$ Embtel 1488, 06.02.1963, pp. 2.

${ }^{49}$ Letter, João Goulart to John Kennedy, 08.03.1963, JFKL, POF, 112, 13, p. 2.

${ }^{50}$ Embtel 1767, 19.03.1963, JFKL, NSF, 13A, BG, 3/12/63-3/21/63.
} 
cia de Desenvolvimento Internacional (Agency of International Development, AID) e o Banco de Exportação e Importação (Export-Import Bank, Eximbank). Desejava-se minimizar os compromissos externos durante a implementação do Plano Trienal. A proposta também incluiu os recursos que seriam solicitados à Europa e ao FMI, que totalizavam US\$ 321 milhões. ${ }^{51}$

As constantes advertências de Goulart sobre a importância de uma substancial assistência externa não comoveram os membros do governo Kennedy. Logo no início das negociações, David Bell, administrador da AID, deixou claro a Dantas que os Estados Unidos não teriam condições de fornecer o montante previsto pela proposta brasileira. Bell salientou também que recursos seriam condicionados ao "desempenho" do governo Goulart em áreas como políticas monetária, cambial e fiscal; teriam distribuição programada para somente um ano; e contariam com mínimas liberações imediatas. Segundo Bell, razões econômicas, tais como o déficit do balanço de pagamentos norte-americano e o histórico brasileiro de quebras de compromissos com planos de estabilização, impediriam o governo Kennedy de agir de outra maneira. ${ }^{52}$

Apesar dos argumentos apresentados por David Bell, é evidente que questões políticas desempenharam o papel de maior peso no curso das negociações. Sempre que possível, as autoridades norte-americanas abordavam o tema da relação de Goulart com "comunistas". O próprio Kennedy ressaltou a Dantas que seria um "grande erro" dar espaço aos comunistas no movimento sindical, visto o "papel-chave desempenhado pelos sindicatos no fortalecimento da democracia". O presidente ressaltou que os comunistas nunca apoiariam um programa como o Trienal, cujo objetivo era o de garantir "ordem e estabilidade". Por isso, "eu acho que seria melhor livrar-se deles agora". Kennedy esclareceu que não enxergava como "comunistas" todos aqueles que fossem "esquerdistas e anti-Estados Unidos, porque estes são inevitáveis". No entanto, "deve ser possível manter o apoio de elementos da esquerda sem depender dos comunistas”. Em sua resposta, o Ministro da Fazenda disse que os comunistas seriam "removidos gradualmente da liderança dos sindicatos", mas que esse processo "estaria condicionado à implementação do plano de estabilização". ${ }^{53}$

Apesar do reconhecido empenho da administração Goulart na aplicação do Plano Trienal, o governo Kennedy não mudou seu posicionamento. No final das negociações, Dantas tentou explicar a Bell que o condicionamento da liberação de recursos ao desempenho em metas de política econômica manteria o clima de "intranquilidade" no Brasil. Os críticos do Plano Trienal, segundo o ministro, acusariam Goulart de estar agindo sob ordens de autoridades estrangeiras, minando o

\footnotetext{
51 “Brazilian Proposal for Debt Re-Scheduling”, 03.1963, Centro de Pesquisa e Documentação de História Contemporânea do Brasil, Fundação Getulio Vargas (a seguir CPDOC), RC d/emb 61.10.19, pasta V.

${ }^{52}$ MemCon, Bell, Dantas, et al., 15.03.1963, NARA, RG 84, 134, 350, pp.7-8.

${ }^{53}$ Idem, pp. 7-10.
} 
programa. O argumento não foi aceito. O governo Kennedy consentiu na liberação imediata de apenas US\$ 84 milhões - e, mesmo assim, sob a condição secreta de Goulart concluir a compra das subsidiárias da AMFORP e de desvalorizar o câmbio para Cr\$ 600,00 por dólar. Os recursos restantes (US\$ 314,5 milhões) seriam distribuídos em até um ano, ficando dependentes do desempenho brasileiro no cumprimento das metas de estabilização do Plano Trienal. Informou-se também que o governo Kennedy poderia rever os termos da ajuda se o governo Goulart não firmasse um stand-by com o FMI até junho de $1963 . .^{54}$

As autoridades brasileiras argumentaram enfaticamente contra a proposta norte-americana. Roberto Campos tentou mostrar ao Departamento de Estado que a oferta "era boa em conteúdo" (afinal, US\$ 400 milhões não era pouco dinheiro), mas não "em forma", pois poucos recursos estariam sujeitos à liberação imediata. Campos assinalou ainda que somente duas alternativas poderiam fortalecer Dantas no Brasil: a obtenção de uma incontestável "vitória" nas negociações, o que enfraqueceria críticos do Plano Trienal; ou o rompimento com os Estados Unidos, “excitando o paroxismo nacionalista, e procurando mobilizar nossos próprios recursos internos pela via do ressentimento e da arregimentação ideológica". Uma "solução intermediária", como a proposta, "conquanto economicamente útil, poderia ser politicamente desastrosa". Diante da inflexibilidade norte-americana, Campos e Dantas chegaram a pensar no rompimento das negociações. Ambos concluíram, porém, que o Brasil ainda não havia atingido o ponto em que "a mobilização do sentimento nacionalista" seria capaz de superar as dificuldades econômicas que adviriam da moratória da dívida externa. ${ }^{55}$ Sem opção, Dantas assinou o acordo. ${ }^{56}$

A divulgação dos resultados da negociação nos Estados Unidos suscitou fortes críticas ao governo Goulart. Os comunistas, por exemplo, acusaram Dantas de ter vendido o Brasil ao "diabo" por um "prato de lentilhas". ${ }^{57}$ As autoridades brasileiras sabiam que as críticas cresceriam quando os compromissos começassem a ser aplicados. Por isso, tentou-se protelar ao máximo a implementação de certas medidas, tal como a aquisição das subsidiárias da AMFORP. A pressão norte-americana, porém, tornou inviável a manutenção dessa tática. Lincoln Gordon ameaçou Goulart com o congelamento da primeira parcela do acordo. O presidente prometeu que o "caso AMFORP" seria solucionado até o dia 19 de abril. ${ }^{58}$

Horas depois do encontro com Gordon, Goulart editou um decreto criando

\footnotetext{
${ }^{54}$ Memo for McGeorge Bundy, 24.03.1963, JFKL, NSF, 13A, 3/22/63-3/31/63. Em um stand-by agreement ("acordo de reserva"), permite-se com que o país beneficiário saque créditos junto ao Fundo, conforme o desempenho em metas pré-acordadas de política econômica. BARRO \& LEE (2005, pp. 1247-8).

55 “Kennedy e o Brasil”, CPDOC, RC d/emb 61.10.19, VII, 01.64, pp. 14-8. Ver também Deptel 1312, 03.1963.

56 “Relatório das negociações da Missão San Tiago Dantas”, CPDOC, RC d/bem 61.10.19, V.

${ }^{57}$ Novos Rumos (a seguir NR), 29.03-04.04.1963, p. 3.

${ }^{58}$ Embtel 1927, 05.04.1963, NARA, RG 84, 136, 501; Embtel 7298, Section II, 09.04.1963, JFKL, NSF, 14, BG, 4/63.
} 
uma Comissão Interministerial com poderes para concluir o negócio da AMFORP, extinguindo a Comissão de Nacionalização das Empresas Concessionárias de Serviços Públicos (CONESP), órgão até então responsável pelo caso. ${ }^{59} \mathrm{O}$ prazo dado por Goulart a Gordon venceu, porém, sem que uma resolução tivesse sido alcançada. O embaixador telegrafou a Washington recomendando congelamento dos fundos enquanto a questão continuasse pendente.$^{60}$ No dia 20 de abril, em reunião extraordinária no Ministério da Guerra, a Comissão Interministerial aprovou por unanimidade os termos de negociação - termos estes que, segundo Dantas, não tinham recebido "apoio unívoco" da extinta CONESP. ${ }^{61}$ Dois dias depois, Roberto Campos assinaria o memorando de entendimento com os representantes da empresa em Washington. ${ }^{62}$

Processo semelhante ao do caso AMFORP ocorreu com a questão cambial. O Ministro da Fazenda havia prometido em Washington desvalorizar o câmbio para Cr\$ 600 por dólar em poucos dias. Passado quase um mês nada havia sido feito. Dantas sabia que o encarecimento das importações, consequência inevitável da depreciação do cruzeiro, geraria demanda de empresários e de trabalhadores por aumentos creditícios e salariais, o que enfraqueceria o programa de estabilização. Já que era preciso concluir um stand-by com o FMI até junho de 1963, a última coisa que se desejava era dar razões para que grupos domésticos criticassem ainda mais o Plano Trienal.

A pressão exercida pelas autoridades norte-americanas impediu o adiamento da questão cambial. Em conversa com Campos, Dean Rusk se disse "decepcionado" com o Ministro da Fazenda e chegou a afirmar que o recém-assinado acordo ficaria comprometido se a desvalorização não fosse decretada "em alguns dias". ${ }^{63}$ Do Brasil, Lincoln Gordon exerceu o mesmo tipo de pressão. Em conversa no dia 21 de abril, Dantas prometeu que a desvalorização ocorreria ainda naquela semana. ${ }^{64}$ No dia seguinte, mesma data da assinatura do memorando de entendimento com a AMFORP, publicou-se "tão aguardada" Instrução 239, estabelecendo a desvalorização do cruzeiro de Cr\$ 460 para Cr\$ 600 por dólar. ${ }^{65}$ Com isso, liberou-se a primeira parcela do acordo Bell-Dantas. ${ }^{66}$

\footnotetext{
59 "Histórico da Operação de compra das ações e direitos da AMFORP”, 1966, CPDOC, RC e/ag 61.02.10 IV-21, p. 15.

${ }^{60}$ Embtel 2035, 19.04.1963, NARA, RG 84, 136, 501.

${ }^{61}$ Para os termos do contrato, ver "Resolução da Comissão Interministerial encarregada de análise da nacionalização das empresas concessionárias de serviços públicos”, 20.04.1963, CPDOC-FGV, RC e/ ag 61.02.10 II 7-12.

${ }^{62}$ Telegrama, Embaixada do Brasil em Washington ao Ministério da Fazenda, 22.04.1963, CPDOC-FGV, RC e/ag 61.02.10 II 7-12.

${ }^{63}$ Deptel 1854, 11.04.1963; e Deptel 1865, 13.04.1963, Idem.

${ }^{64}$ Embtel 2061, 22.04.1963, Idem.

${ }^{65}$ Embtel A-1224, 25.04.1963, NARA, RG 84, 465, 501, p. 1.

${ }^{66}$ Embtel 2008, 15.04.1963, NARA, RG 84, 136, 501.
} 
Como esperado, essas medidas geraram fortes críticas ao governo Goulart. Grupos de esquerda reclamaram dos efeitos negativos da Instrução 239 para a classe trabalhadora ${ }^{67}$ As censuras pela compra das subsidiárias da AMFORP foram ainda maiores. Chamou-se o Brasil de "palhaço do hemisfério" por adquirir "ferro velho" a "preço de ouro". ${ }^{68}$ Duas Comissões Parlamentares de Inquérito foram montadas para investigar o assunto. ${ }^{69}$ Deputados federais chegaram a ameaçar Goulart com "impeachment" caso o acordo fosse mantido. ${ }^{70}$ Segundo a embaixada norte-americana, a campanha da esquerda contra a AMFORP estaria "ofuscando todas as demais questões políticas". ${ }^{71}$

Havia outro assunto que incomodava profundamente os setores esquerdistas: o apoio do presidente Goulart à criação de uma nova central sindical, denominada União Sindical dos Trabalhadores (UST)..$^{72}$ Desde janeiro de 1963, Goulart expressava o desejo de pôr em prática "algum plano para reduzir o poder dos comunistas" nos sindicatos, especificamente o papel do Comando Geral dos Trabalhadores (CGT) ${ }^{73}$ No início de maio, sob a coordenação do assessor sindical da Presidência, Gilberto Crockat de Sá, a nova central foi montada. A UST representava a concretização de antiga demanda norte-americana: a necessidade de Goulart romper com os comunistas no movimento sindical. ${ }^{74}$ Segundo relato do adido trabalhista norte-americano, Luís Carlos Prestes teria inclusive pedido a Goulart para não levar adiante o projeto. ${ }^{75} \mathrm{~A}$ montagem da UST daria ainda mais fôlego às críticas da esquerda ao Plano Trienal e, em particular, ao acordo com a AMFORP.

As concessões de Goulart em áreas como política econômica, relacionamento com investidores estrangeiros e movimento sindical levaram autoridades norte-americanas a afirmar que o presidente brasileiro estaria apresentando indícios de "uma mudança de coração". ${ }^{76}$ Parecia que o objetivo do "programa passo a passo" estava sendo alcançado, isto é, a criação de um racha entre Goulart e os "comuno-nacionalistas”. ${ }^{77}$ Para fortalecer essas divisões e dar sustentação política a Jango,

\footnotetext{
${ }^{67} \mathrm{NR}, 219,01.05-09.05 .1963$, p. 3.

${ }^{68}$ Embtel 2331, 01.06.1963, JFKL, NSF, 14, BG, 6/63, p. 1.

${ }^{69}$ Embtel Brasília 228, 08.06.1963, NARA, RG 84, 136, 500.8; OESP, 05.06.1963, p. 2.

${ }^{70}$ Idem, pp. 2-3.

${ }^{71}$ Embtel 2328, 31.05.1963, NARA, RG 84, 136, 501, p. 1.

${ }^{72}$ Idem, p. 3.

${ }^{73}$ Embtel 1345, 17.01.1963, JFKL, NSF, 13A, BG, 1/63, p.3; e "Labor Developments in Brazil”, s/d, Folder BG, 3/1/63-3/11/63, p. 2.

${ }^{74}$ Embtel 106, Section II, 17.07.1963, Idem, 14, BG, 7/16/63-7/31/63, p. 1.

${ }^{75}$ Embtel 146, 10.05.1963, Ibidem, BG, 5/1/63-5/10/63.

${ }^{76}$ Deprep A-1284, 09.05.1963, Ibidem, p. 5.

${ }^{77}$ Embrep A-941, “Apparent divergence among elements of Brazilian left", 18.02.1963, Ibidem, 13A, BG 2/63.
} 
no entanto, fazia-se necessário compensar o enfraquecimento da base esquerdista do presidente com um incontestável suporte internacional. Essa foi a argumentação usada sem sucesso por Roberto Campos nas negociações em Washington. Em maio de 1963, porém, com a chegada de uma missão do FMI ao Rio de Janeiro, teve-se uma segunda chance para consolidar a "mudança de coração" de Goulart. A assinatura de um empréstimo stand-by com o Fundo - abrindo perspectivas para a obtenção de recursos dos Estados Unidos e da Europa - representaria uma significativa vitória, contrabalançando ataques da esquerda ao governo e consolidando a abordagem moderada de Goulart. Por outro lado, qualquer outro resultado manteria o presidente em frágil situação política.

Lincoln Gordon percebeu a importância dos resultados da missão do FMI. Em comunicado a Washington, o embaixador "exortou" o Departamento de Estado a influenciar o Fundo a flexibilizar exigências, visando "minimizar oportunidades para aqueles que desejam sabotar um genuíno entendimento" com o governo brasileiro. Conforme Gordon, se algumas metas do Plano Trienal não estavam sendo cumpridas como esperado, tinha-se de admitir também que pressões de empresários e de trabalhadores constituiriam um "fator concreto, o qual esperamos que serão reconhecidos". O embaixador disse acreditar em "uma área no Brasil onde viabilidade política e solidez econômica" poderiam "ser reconciliadas". ${ }^{78}$

As recomendações de Gordon surtiram efeito, mas não na intensidade necessária. O Fundo decidiu emprestar US\$ 60 milhões como compensação pelo declínio no valor das exportações do Brasil. Mesmo assim, esses recursos só teriam sido aprovados devido à pressão dos representantes norte-americanos, que "enfatizaram o esforço de cooperação do governo brasileiro". ${ }^{79} \mathrm{O}$ aval do Fundo era importante para Washington porque abria a perspectiva de os Estados Unidos dividirem com os europeus o suporte financeiro ao Brasil. ${ }^{80} \mathrm{~A}$ diretoria do FMI deliberou, no entanto, que a concessão do empréstimo não significaria apoio à política econômica do governo Goulart, ou, muito menos, de que um stand-by estaria a caminho.$^{81}$ Minaram-se, assim, as chances de um acordo com o Fundo no curto prazo. ${ }^{82}$

As implicações da negativa do FMI foram grandes. Sem o aval do Fundo, a Europa não negociaria empréstimos. As consequências nas contas brasileiras seriam graves, pois se esperava contar com US\$ 120 milhões dos europeus em 1963. Além disso, não se tinha clareza sobre o que aconteceria com o acordo Bell-Dantas sem o suporte do FMI. O Plano Trienal já não estava mais sendo seguido à risca, prin-

\footnotetext{
${ }^{78}$ Embtel 2112, Section III, 30.04.1963, JFKL, NSF, 14, BG, 4/63, pp. 3-4.

${ }^{79}$ Report, IMF British Director to the Foreign Office, 09.06.1963, TNA, FO 371/172354, p. 3.

${ }^{80}$ Telecom, George Ball and Hamilton, 07.09.1962, JFKL, PPGB, 1, Brazil 4/20/61-7/10/63.

${ }^{81}$ Report, IMF British Director, 09.06.1963, pp. 6-7.

${ }^{82}$ Embtel 2320, 30.05.1963, NARA, RG 84, 136, 501.
} 
cipalmente suas políticas creditícia e salarial. Pressionado pela esquerda, o governo Goulart passou a defender a flexibilização dos compromissos acertados em Washington, em particular os termos com a AMFORP. Queria-se que a avaliação dos ativos das subsidiárias fosse feita antes da assinatura do contrato de compra. Assim, seria possível ajustar o valor final conforme o resultado do inventário de bens. A empresa concordou em antecipar o inventário, contanto que o Brasil se comprometesse a pagar o mesmo preço (US\$ 142,7 milhões). Em resposta, San Tiago Dantas afirmou que a postura da companhia "poderia causar problema". ${ }^{33}$ Segundo o ministro, seria "imprudente e até mesmo perigoso" seguir à risca o acordo diante da "forte oposição" doméstica. ${ }^{84}$

As demandas brasileiras por concessões do governo Kennedy não surtiram efeito. Apesar de reconhecer as "reais dificuldades" que Goulart estava enfrentando, Washington não flexibilizou suas exigências. ${ }^{85} \mathrm{O}$ fracasso na obtenção de um stand-by com o FMI e a quebra de compromisso no caso AMFORP levaram o governo Kennedy a congelar os recursos do acordo Bell-Dantas. ${ }^{86}$ Futuras liberações só ocorreriam quando as metas do Plano Trienal fossem atualizadas, assegurando o compromisso com a estabilidade econômica. ${ }^{87}$ Segundo o Secretário de Estado, o contingenciamento de recursos também se basearia no "caso AMFORP", o qual, "apesar de não ser a mais importante questão das relações EUA-Brasil, transformou-se em um teste de boa-fé e de capacidade de Goulart" em resistir às pressões das esquerdas. ${ }^{88}$

A inflexibilidade norte-americana levou Goulart a mudar de postura. Segundo Gordon, em agosto de 1963 o Plano Trienal já havia sido abandonado, o governo declinara da assinatura de um contrato com a AMFORP e Goulart retirara seu apoio à UST, voltando a atuar no movimento sindical junto aos "comuno-nacionalistas".$^{89}$ Nesse contexto, o presidente Kennedy confessou a Roberto Campos que "perdia noites pensando no Brasil". Campos respondeu que, em parte, essa insônia seria culpa dos próprios Estados Unidos: Washington não teria tido "visão suficiente para enfrentar um moderado risco financeiro". "Agora”, acrescentou, "os Estados Unidos estavam correndo um grande risco político" $\cdot{ }^{90}$ Aceleravam-se, assim, as condições que desembocariam no golpe de março de 1964.

\footnotetext{
${ }^{83}$ Embtel 2387, 10.06.1963, NARA, RG 84, 136, 500.1, p. 1.

${ }^{84}$ Embtel 2336, Section I, 02.06.1963, Idem, p. 1.

${ }^{85}$ Embtel 246, 02.08.1963, JFKL, NSF, 14, BG, 8/1/63 - 8/20/63.

${ }^{86}$ Deptel 2184, 07.06.1963, NARA, RG 84, 136, 500.8.

${ }^{87}$ Embtel 20, Section I, 03.07.1963, JFKL, NSF, 14, BG, 7/11/63 - 7/15/63.

${ }^{88}$ Deptel s.n., 29.06.1963, JFKL, NSF, 14, BG, 6/63, p. 2.

${ }^{89}$ Embtel A-254, 21.08.1963, JFKL, NSF, 14, BG, 8/21/63 - 8/31/63, pp. 5-6.

90 “Kennedy e o Brasil”, s.d., p. 19; e MemPres, 28.08.1963, Idem, p. 1.
} 


\section{CONCLUSÕES}

O governo Kennedy concedeu reduzido suporte financeiro ao Plano Trienal, contribuindo significativamente para o malogro do programa. O principal motivo dessa atitude foi político. Washington desconfiava das ligações do presidente Goulart com "comunistas". Já ao final de 1962 decidiu-se que a concessão de recursos deveria estar condicionada a um "programa passo a passo", um conjunto de medidas visando comprometer as ligações do presidente Goulart com a esquerda radical, tais como a execução de um rígido plano de estabilização e o pagamento de "justas indenizações" a empresas norte-americanas. O fato de essas demandas coincidirem com poderosos interesses econômicos privados apenas reforçava a sua indispensabilidade.

Houve um momento em que o presidente brasileiro deu indícios de que estava disposto a ceder. No início de 1963 Goulart apoiou a execução de um rígido programa de estabilização, autorizou o pagamento de uma "justa indenização" à ITT, concordou com a assinatura de um polêmico acordo com a AMFORP e, o mais importante, deu passos para romper com os comunistas no movimento sindical. A única coisa que o presidente não fez foi expurgar totalmente esquerdistas do governo. Para isso, Goulart precisava de um inequívoco apoio internacional, bem como do suporte de grupos moderados domésticos, protegendo-o dos setores golpistas de direita. Além disso, a fim de esvaziar um possível apoio social à extrema esquerda, era necessário que o Plano Trienal amadurecesse. Como argumentou Dantas nos Estados Unidos, com altas taxas de crescimento, baixa inflação e possibilidade de concessão de aumentos salariais reais, um rompimento entre Goulart e a esquerda radical dar-se-ia naturalmente. No entanto, Washington foi inflexível. Antes de conceder uma ajuda significativa, o governo Kennedy queria que Goulart cedesse em todos os aspectos. Isso Goulart não estava disposto a fazer. O impasse foi rompido com o abandono do Plano Trienal.

É importante enfatizar de que modo essas conclusões pretendem contribuir para a extensa literatura sobre o fracasso do Plano Trienal. Considera-se que uma das principais explicações sobre o tema, referente ao aguçamento das tensões sociais domésticas e à pressão das entidades de empresários e de trabalhadores em prol da flexibilização das metas de estabilização, está essencialmente correta. Argumenta-se, entretanto, que essa abordagem que prioriza fatores internos só adquire sentido de uma perspectiva que englobe as relações diplomáticas entre Brasil e Estados Unidos no período. Isso porque, para viabilizar a implementação do Plano Trienal em meio a tal conflito distributivo, era fundamental que o governo Goulart abrandasse seus objetivos de política econômica, ampliando o período de estabilização da economia de três para, digamos, cinco ou seis anos. Isso permitiria a suavização das políticas monetária, cambial e fiscal, de modo a impedir que as pressões de empresários (via remarcação de preços) e de trabalhadores (via greves) obstruíssem o sucesso do programa. O artigo mostra, porém, que essa saída não foi possível devido às restrições externas, particularmente ao posicionamento do 
governo norte-americano, que insistiu, entre outras coisas, na aplicação de uma rígida política de estabilização pelo Brasil em troca da liberação de recursos.

Vale perguntar, por fim, se a inflexibilidade de Washington não teria sido perigosa para os interesses norte-americanos. Ao que parece, não. O risco de alinhamento brasileiro com o bloco comunista era muito pequeno. Sabia-se que a União Soviética não tinha condições de substituir os Estados Unidos como principal parceiro comercial do Brasil, ao menos em um primeiro momento. Além disso, após o recuo soviético na crise dos mísseis de Cuba de outubro de 1962, a posição norte-americana fortaleceu-se no hemisfério. Washington pôde ser firme com Goulart porque sabia que o Brasil não tinha alternativa. O problema é que a carreira política de Goulart tinha. O presidente brasileiro demonstrou que preferia ser derrubado como um político identificado no imaginário popular como uma figura progressista e símbolo da luta pelas reformas de base do que ficar refém de setores domésticos de extrema direita. Por essa lógica, o abandono do Plano Trienal, bem como das outras facetas da moderação janguista, fazia sentido. A única coisa que Goulart não esperava era o surgimento de uma longa ditadura, que impediria por mais de um quarto de século a realização de eleições presidenciais no país.

\section{REFERÊNCIAS BIBLIOGRÁFICAS}

ABREU, Marcelo (org.). (1990). A Ordem do Progresso. Cem Anos de Política Econômica Republicana (1889-1989). Rio de Janeiro: Campus.

ARAÚJO, Victor, et al. (2006). "A política macroeconômica e o reformismo social: impasses de um governo sitiado”. In: Marieta Ferreira (org.). João Goulart: Entre a Memória e a História. Rio de Janeiro: FGV Editora.

BAER, Werner. (1979). A Industrialização e o Desenvolvimento Econômico do Brasil. $4^{\text {a }}$ Edição. Rio de Janeiro: Fundação Getulio Vargas.

BANDEIRA, Moniz (1983). O Governo João Goulart: As Lutas Sociais no Brasil (1961-64). 6 a Edição. Rio de Janeiro: Civilização Brasileira.

BARRO, Robert and LEE, Jong-Wha (2005). "IMF programs: who is chosen and what are the effects?", Journal of Monetary Economics, 52:1245-69.

BRASIL (1962). Presidência da República. Plano Trienal de Desenvolvimento Econômico e Social. Sintese. Rio de Janeiro: Imprensa Nacional.

CASTRO, Paulo e RONCI, Márcio (1992). “Sesenta años de populismo en el Brasil.” In: Rudiger Dornbusch et al. (org.). Macroeconomia del Populismo en la America Latina. México: Fondo de Cultura, p. 176-98.

DALAND, Robert (1967). Estratégia e Estilo de Planejamento Brasileiro. Rio de Janeiro: Lidador.

DULLES, John (1970). Unrest in Brazil. Political-military crisis (1955-1964). Austin: University of Texas Press.

FERREIRA, Jorge (2011). João Goulart. Uma Biografia. Rio de Janeiro: Civilização Brasileira. e GOMES, Ângela de C. (2007). Jango. As Múltiplas Faces. Rio de Janeiro: FGV Editora.

FICO, Carlos (2004). Além do Golpe: Versões e Controvérsias sobre 1964 e a Ditadura Militar. São Paulo: Record.

FIGUEIREDO, Argelina (1993). Democracia ou Reformas? Alternativas Democráticas à Crise Política, 1961-1964. São Paulo: Paz e Terra.

FONSECA, Pedro (2004). "Legitimidade e credibilidade: impasses da política econômica do Governo Goulart”, Estudos Econômicos. 34(6):587-622. 
LEACOCK, Ruth (1990). Requiem for Revolution: The United States and Brazil, 1961-1969. Kent: Kent State University Press.

LEFF, Nathaniel (1977) "Política econômica e Desenvolvimento no Brasil, 1947-1964". Perspectiva, São Paulo, 1977.

LOUREIRO, Felipe (2010). "Uma difícil conciliação: empresários e trabalhadores no contexto do Plano Trienal", História Econômica e História de Empresas, 13(2):109-43.

LOUREIRO, Felipe (2012). "Empresários, trabalhadores e grupos de interesse: a política econômica nos governos Jânio Quadros e João Goulart”. Tese de Doutorado, FFLCH/USP.

MACEDO, Roberto (1987). "O Plano Trienal de Desenvolvimento Econômico e Social, 1963-1965”. In: Betty Lafer (org.). Planejamento no Brasil. São Paulo: Perspectiva, 52-67.

MESQUITA, Mário (1992). “1961-1964: A política econômica sob Quadros e Goulart”. Rio de Janeiro: Dissertação de Mestrado, PUC-RJ.

MIRANDA, Samir (2006). "Projeto de desenvolvimento e encampações no discurso do governo Leonel Brizola: Rio Grande do Sul (1959-1963)”. Porto Alegre: Dissertação de Mestrado, UFRGS.

MONTEIRO, Sérgio (1999). "Política Econômica e Credibilidade: uma análise dos governos Jânio Quadros e João Goulart”. Porto Alegre: Tese de Doutorado, UFRGS.

SILVA, Ricardo (1992). "Política e política econômica na crise do início dos anos sessenta: o Plano Trienal de Desenvolvimento Econômico e Social (1963-1965)”. Campinas: Dissertação de Mestrado, Unicamp.

SOCHACZEWSKY, Antônio (1991). Desenvolvimento Econômico e Financeiro do Brasil (1952-1968). São Paulo: Trajetória Cultural.

SOLA, Lourdes (1998). Ideias Econômicas, Decisões Políticas. São Paulo: Edusp.

STORRS, Keith (1973). “Brazil's Independent Foreign Policy, 1961-1964: Background, Tenets, Linkage to Domestic Politics, and Aftermath”. New York: PhD diss., Cornell University.

WELLS, John (1977). "Growth and fluctuations in the Brazilian manufacturing sector during the 1960's and early 1970's”. Cambridge: PhD diss., Cambridge University. 